\title{
Advances in the Treatment of Behcet's Disease
}

\author{
Fatma Alibaz-Oner ${ }^{1}$ (D) $\cdot$ Haner Direskeneli ${ }^{1}$ (D)
}

Accepted: 23 March 2021 / Published online: 20 May 2021

(C) The Author(s), under exclusive licence to Springer Science+Business Media, LLC, part of Springer Nature 2021

\begin{abstract}
Purpose of Review To assess current management of Behcet's disease (BD). Controversies on therapeutic approaches to different manifestations, whether conventional immunosuppressives (IS) or biologic agents, should be chosen, and options for refractory disease are discussed.

Recent Findings Glucocorticoids are still the main agents for remission-induction and azathioprine the first-line conventional IS in maintenance phase to prevent relapses of major organ involvement. Apremilast is shown to be a safe and effective option approved by the FDA for oral ulcers. Large case series confirmed the efficacy and safety of TNF $\alpha$ inhibitors and Interferon- $\alpha$. Promising results are observed with IL-1 inhibitors, ustekinumab, secukinumab, and tocilizumab for refractory BD.

Summary Although both conventional IS and biologic agents are effectively used to suppress inflammation in BD, there is still an unmet need for clear therapeutic strategies in the management for different manifestations. Further controlled studies with new biologic agents, anticoagulants and the benefit of concomitant IS usage with biologics are needed to optimize the management of BD.
\end{abstract}

Keywords Behcet's disease $\cdot$ Treatment $\cdot$ Biological agents $\cdot$ Conventional immunosuppressives

\section{Introduction}

Behcet's disease (BD) is a chronic, multisystemic, inflammatory syndrome characterized by recurrent attacks of oralgenital ulcers, skin lesions, and ocular, musculoskeletal, vascular, central nervous system (CNS), and gastrointestinal (GI) involvements (Table 1). Despite optimal immunosuppressive (IS) treatments, relapses are common, and disease-related damage develop in a significant subgroup of patients, especially in ones with ocular, vascular, and neurological involvement. Young males are the group with the highest risk of morbidity and mortality [1]. As a multi-systemic disorder, management of BD requires a thorough evaluation of the se-

This article is part of the Topical Collection on Vasculitis

Haner Direskeneli

hanerdireskeneli@gmail.com

Fatma Alibaz-Oner

falibaz@gmail.com

1 Division of Rheumatology, Department of Internal Medicine, Marmara University School of Medicine Hospital, Fevzi Çakmak Mahallesi, Ust-Kaynarca, Pendik, Istanbul, Turkey verity and damage risk of different manifestations in each patient visit.

Colchicine, non-steroidal anti-inflammatory drugs (NSAIDs) and topical/low-dose oral treatment with glucocorticoids (GC) are often sufficient for mucocutaneous (MC) and joint involvement, whereas major organ disease such as ocular, vascular, neurological, and gastro-intestinal manifestations are treated with long-term immunosuppression. However, each manifestation has its own subsets of "mild vs severe" forms such as anterior vs posterior uveitis/retinitis or dural sinus thrombosis vs parenchymal neurological disease. Careful assessment of long-term damage risk is thus essential to determine the duration of treatment, choice of IS agents, and an adequate protection of patients from $\mathrm{GC}$-associated drug toxicities.

The pathogenesis of BD is poorly understood. As activation of neutrophils and monocytes leading to interleukin-1 (IL-1) release is observed, BD is accepted by some as an autoinflammatory disease. However, autoimmune T-cell responses and spondyloarthropathic features are also observed [2]. In the light of recent data elucidating the pathogenesis, biologic treatments targeting proinflammatory cytokines or intra-cellular pathways are important new therapeutic options for BD. In this review, we aimed to summarize the current treatment approaches in light of recent studies and personal experiences of a tertiary Behcet's Center. 
Table 1 Frequency of different manifestations of Behcet's disease

\begin{tabular}{ll}
\hline Manifestation & Frequency (\%) \\
\hline Oral ulcers & $97-99$ \\
Genital ulcers & $80-85$ \\
Papulopustular lesions & $75-85$ \\
Erythema nodosum & $40-50$ \\
Pathergy reaction & $30-50$ \\
Uveitis & $40-50$ \\
Arthritis & $30-50$ \\
Deep vein thrombosis & $10-15$ (more prevalent around \\
& Mediterranean) \\
Arterial occlusion/aneurysm & $5-10$ (more prevalent around \\
Central nervous system & Mediterranean) \\
$\quad$ involvement & $5-10$ \\
Epididymitis & $2-3$ \\
Gastrointestinal lesions & $2-50$ (more prevalent in Japan/Korea)
\end{tabular}

\section{Conventional Immunosuppressives}

Most mild forms of major organ involvement are sufficiently controlled by conventional ISs (cISs) such as GCs, azathioprine, cyclosporine A, and mycophenolate mofetil (MMF). Comparative controlled data, especially in uveitis patients, show the efficacy of cISs as the first-line treatment also in severe major organ involvement [3]. However, there is currently limited data on the role of cISs in routine practice, leading to an overuse of biologics especially for mild major organ disease. In our series, $59 \%$ of patients with BD uveitis are treated with cISs such as azathioprine and cyclosporine A, with GCs used as necessary "bridging" therapy [4].

Although widely used as low dose $(5-10 \mathrm{mg}$ /day prednisolone) for MC manifestations and high-dose (0.5-1 $\mathrm{mg} / \mathrm{kg} /$ day prednisolone)/pulse (0.5-1 g methylprednisolone) regimens for remission-induction of major organ disease, studies on the optimal dose and duration of GCs, as well as the extent of GC-associated damage are limited with controversial results in $\mathrm{BD}[5,6]$. Interestingly, in a validation cohort of a recently developed Behcet's syndrome overall damage index (BODI), "ever use of GCs" are not found to be associated with overall damage score [7]. This surprising observation either reflects the young age and overall lack of comorbidities in BD population or the limitation of the tool to adequately assess GC-related damage. Azathioprine, a cornerstone of mild major organ involvement, is also possibly efficacious for the prevention of the most new-onset major organ BD in patients with mucocutaneous onset, such as gastrointestinal involvement, anterior uveitis, or venous vascular disease, and can be a prophylactic agent [8] (unpublished observations).

\section{Biologic Treatments}

Although randomized-controlled trials (RCT) are lacking, many biologic agents targeting proinflammatory cytokines, such tumor necrosis factor alpha (TNF $\alpha)$, IL-1, IL-6, IL12, and IL-17 licensed for other rheumatological disorders, became part of the treatment choices in BD. A broad consensus emerging from the case series and few RCTs suggest that TNF $\alpha$ inhibitors and Interferon (IFN)- $\alpha$ are effective for the most common major organ involvements in $\mathrm{BD}$, namely, ocular and vascular disease. Among TNF $\alpha$ inhibitors, monoclonal antibodies are more effective than the soluble forms - similar to the situation in inflammatory bowel disease.

A recent controversial issue of biologic use is the "optimization" of advanced therapies in BD before discontinuation. Among biological agents, both infliximab (IFX) and IFN $\alpha$ have flexibilities for dose adjustment in both remissioninduction and maintenance use. IFX is usually started at 3$10 \mathrm{mg} / 0-2-6$ weekly and then every $4-8$ weeks. In a recent study, after complete remission, IFX dose was decreased to $3-$ $5 \mathrm{mg} / \mathrm{kg}$ every $8-12$ weeks with similar outcomes as compared to the standard regimen of $5 \mathrm{mg} / \mathrm{kg}$ every 8 weeks. The authors calculated a $51 \%$ annual cost reduction by dose reduction [9]. Similarly, our group suggested a low-dose remission-induction ( 3 million IU/day-14 days) and maintenance ( 3 million IU/3 weekly) regimen with IFN $\alpha$, with dose escalations if necessary [10].

Recently, biosimilars are also used in BD patients. Although a first study has shown a loss of efficacy in 3 patients after switch to an IFX biosimilar, subsequent studies reported good efficacy and safety profile of IFX biosimilar after a start or switch from the originator [11-14].

Some of the critical questions that are unresolved in $\mathrm{BD}$ management are similar to other multi-systemic disorders such as systemic lupus erythematosus and vasculitides. These are the duration and choice of treatments for remission-induction, duration/discontinuation of therapies during remission, "treat-to-target" strategies and whether GC can be stopped early.

Finally, although biologic agents seem to be safely continued in the COVID-19 era in rheumatological disorders, the reluctance of patients and physicians to start new biologics due to safety concerns require a careful approach in decisions of switching from cISs to biologics, especially in mild forms of organ involvement in BD patients [15].

\section{Treatment of Organ Manifestations}

Our expert-opinion approach to the management of different organ manifestations in BD is summarized in Table 2. 


\section{Mucocutaneous Manifestations}

Behcet's disease usually starts with mucocutaneous manifestations which have a limited impact on vital organ functions and general quality of life (QoL). Despite conflicting results of controlled studies, colchicine alone or combined with shortterm topical GCs is considered as the first-line treatment for oral/genital ulcers and nodular-type skin manifestations in daily practice due to its safety and tolerability. Similarly, "2018 EULAR recommendations for the Management of BD" suggests topical GCs/colchicine as first-line of treatments for oral/genital ulcers, papulopustular, and acne-like lesions $[16 \bullet \bullet$

This safe approach, however, leads to an insufficient suppression of mucocutaneous symptoms. Up to $60 \%$ of the patients followed in our cohort had at least one oral ulcer in the last month before each clinical visit, demonstrating the "unmet need" in routine practice [17]. A close look at especially oralQoL studies also suggest that patients are usually uncomfortable with their frequency of oral ulcers under colchicine/ topical treatments. Although a study with depo methylprednisolone preparation did not show any benefit on oral/genital ulcers [5], a significant subset of patients with oral ulcers can be managed with oral low-dose prednisolone ( $<7.5 \mathrm{mg}$ /day) intermittently in our clinic with favorable results (unpublished observations).

Thalidomide is not used in daily practice due to its side effects, especially irreversible neurotoxicity even at low doses. Among TNF $\alpha$ inhibitors, only etanercept was studied in a randomized controlled, 4-week trial in male $\mathrm{BD}$ patients and significantly decreased the number of oral ulcers and erythema nodosum-like lesions compared to placebo [18]. Several observational studies and case series also confirmed the beneficial effects of IFX and adalimumab (ADA) on mucocutaneous lesions [19]. According to these data, TNF $\alpha$ inhibitors can be considered for resistant MC lesions in $\mathrm{BD}[16 \bullet \bullet]$.

Apremilast, an oral phosphodiesterase-4 inhibitor, was observed to be effective in suppressing oral ulcers in a phase 2 study [20]. A phase 3, multicenter, placebo-controlled 52week study which included 207 patients with BD who had active ulcers (but no major organ involvement) confirmed the efficacy of apremilast $30 \mathrm{mg} /$ bid $[21 \bullet \bullet]$. No major differences were observed between the groups for serious side effects, but diarrhea, nausea, and headache were more common in the apremilast group. Apremilast is now approved by the FDA for oral ulcer treatment in BD patients. Recent case series supported the efficacy of apremilast in real life; however, $28 \%(7 / 25)$ of patients stopped apremilast due to side effects $[22,23]$. Apremilast-colchicine combination also seemed to work well in a recent observational study [24]. With a good safety profile without an increase in infections and malignancies, apremilast may become the second-line choice after colchicine for MC manifestations of $\mathrm{BD}$ in countries where it is reimbursed. However, the high cost of the original molecule may influence its approval by reimbursement authorities for only MC manifestations in some countries until generic forms become available. Present data do not allow any conclusions

Table 2 Approach to the management of different organ presentations in BD

\begin{tabular}{|c|c|c|c|}
\hline Disease manifestation & First-line treatments & Second-line treatments & Experimental treatments \\
\hline Mucocutaneous & $\begin{array}{l}\text { Colchicine } \\
\text { Glucocorticoids (low-dose oral/topic) }\end{array}$ & $\begin{array}{l}\text { Azathioprine } \\
\text { Apremilast } \\
\text { TNF } \alpha \text { inhibitors Interferon- } \alpha\end{array}$ & $\begin{array}{l}\text { Anti-IL1 } \\
\text { Ustekinumab } \\
\text { Secukinumab }\end{array}$ \\
\hline Articular & $\begin{array}{l}\text { Colchicine } \\
\text { Salazopyrin } \\
\text { Methotrexate }\end{array}$ & $\begin{array}{l}\mathrm{TNF} \alpha \text { inhibitor } \\
\text { Interferon- } \alpha\end{array}$ & $\begin{array}{l}\text { Anti-IL-1 } \\
\text { Secukinumab }\end{array}$ \\
\hline Ocular & $\begin{array}{l}\text { Azathioprine } \\
\text { Cyclosporine A }\end{array}$ & $\begin{array}{l}\mathrm{TNF} \alpha \text { inhibitors } \\
\text { Interferon- } \alpha\end{array}$ & Tocilizumab \\
\hline Vascular & $\begin{array}{l}\text { Azathioprine }(\mathrm{V}, \mathrm{A}) \\
\text { Cyclosporine } \mathrm{A}(\mathrm{V}) \\
\text { Cyclophosphamide (A) }\end{array}$ & $\begin{array}{l}\mathrm{TNF} \alpha \text { inhibitors } \\
\text { Interferon- } \alpha\end{array}$ & Tocilizumab \\
\hline Neurological & $\begin{array}{l}\text { Azathioprine } \\
\text { Mycophenolate mofetil }\end{array}$ & $\begin{array}{l}\text { TNF } \alpha \text { inhibitors } \\
\text { Interferon- } \alpha \\
\text { Cyclophosphamide }\end{array}$ & Tocilizumab \\
\hline Gastrointestinal & $\begin{array}{l}\text { Salazopyrin } \\
\text { Azathioprine }\end{array}$ & $\mathrm{TNF} \alpha$ inhibitors & $\begin{array}{l}\text { Anti-IL-1 } \\
\text { Tocilizumab }\end{array}$ \\
\hline
\end{tabular}

$V$ venous, $A$ arterial

Dosing, colchicine $0.5-2 \mathrm{mg} /$ day; azathioprine, $2-2.5 \mathrm{mg} / \mathrm{kg} /$ day, glucocorticoids: low-dose, $5-10 \mathrm{mg} /$ day prednisolone; Salazopyrin, $0.5-3 \mathrm{~g} /$ day, methotrexate, 5-25 mg/week; cyclophosphamide, $0.5-1 \mathrm{~g} / \mathrm{month}$; cyclosporine A, 3-5 mg/kg/day; mycophenolate mofetil, 0.5-3 g/day; apremilast, 60 $\mathrm{mg}$ /day; Interferon- $\alpha$, 3-9 million IU/3-7 d weekly; TNF $\alpha$ inhibitors: infliximab, 3-10 mg/kg/4-8 weekly, adalimumab, $40 \mathrm{mg} / \mathrm{SC} / 1-2 \mathrm{weekly}$; IL-1 antagonists: anakinra, 100-200 mg/SC daily; canakinumab, $150-300 \mathrm{mg} / 2-4$ weekly; tocilizumab, 4-8 mg/kg/4 weekly, $162 \mathrm{mg} / \mathrm{weekly} \mathrm{SC}$; ustekinumab, 45-90 mg/4-8 weekly; secukinumab, 150-300 mg/4-8 weekly 
on whether apremilast prevents or is effective for major organ involvement in $\mathrm{BD}$ and requires further studies.

Other biological agents have been studied in case series in BD patients with refractory MC symptoms. There are few series showing efficacy of IL-1 blockage in BD with MClimited disease $[25,26]$. In a study by Grayson et al., complete $(n=2)$ or partial responses $(n=3)$ were observed in 5 of 6 patients with anakinra $200 \mathrm{mg} /$ day in 6 months. Increasing anakinra to $300 \mathrm{mg} /$ day did not result in further improvement [27]. In another study of 36 patients, flares during long-term (> 12 month) treatment were frequent for MC symptoms [28•]. In two open-label prospective studies, ustekinumab, a humanized monoclonal antibody targeting IL-12/IL-23, appeared to be effective for the treatment of oral ulcers in patients with BD resistant to colchicine [29, 30]. According to other case reports, tocilizumab seems to be ineffective for MC manifestations or might even lead to paradoxical exacerbations [31, 32]. A retrospective case series reported that secukinumab may be safe and effective for the treatment of patients with $\mathrm{MC}$ and articular involvement [33•].

Our first choice for refractory oral ulcers, however, is still azathioprine, as it might also decrease the risk of new major organ involvement with a good safety profile. Other MC symptoms such as genital ulcers and follicular and nodular lesions are either responsive to colchicine, antibiotics, or low-dose GCs or do not relapse frequently (azathioprine is rarely required).

Management of leg ulcers associated with deep vein thrombosis and chronic arterial ischemia should be planned with experienced dermatologists and vascular surgeons, since evidence is currently limited to expert opinion. Treatment options include ISs (especially when leg ulcers are associated with pyoderma gangrenosum), antibiotics if infection is present, debridement, or occlusive measures.

\section{Joint Involvement}

Joint involvement in BD is usually monoarticular, non-erosive, and present with self-limiting attacks of short duration. Intra-articular GCs may help in acute monoarticular disease. Most patients with articular BD are responsive to colchicine, sulfasalazine, or methotrexate. Rare cases necessitating biologics have usually a spondyloarthropathic like course with axial involvement. TNF $\alpha$ inhibitors should be chosen first in these cases. INF $\alpha$, anti-IL-1 therapies, or secukinumab may be tried in further refractory cases.

\section{Ocular Involvement}

Azathioprine or cyclosporine A are traditionally first-line treatment options for the treatment of ocular involvement since their efficacy for protecting visual acuity and preventing uveitis relapses were confirmed in RCTs [34-37]. INF $\alpha$ is a widely used alternative for the treatment of ocular involvement $[38,39]$. INF $\alpha$ have immunomodulatory effects in BD with suppression of Th17 cells, increase of IL-10 expression, and recovery of Treg function [40 $]$. In a literature review, IFN $\alpha$ was found effective for all manifestations of BD. Almost all (94\%) patients with ocular involvement achieved partial or complete remission within 2-4 weeks of IFN $\alpha$ treatment. Complete remission rate was better in patients treated with higher ( $>3$ million IU) IFN $\alpha$ dosages [41]. In long-term follow-up studies (mean 8 years), at least half of patients with ocular involvement remained in remission for 5 years of follow-up after the discontinuation of IFN $\alpha$ (usually with 2 years of treatment) $[42,43]$. In a prospective head-to-head RCT comparing IFN $\alpha$ with cyclosporine A, IFN $\alpha$ was better in ocular remission rates, maintenance of visual acuity, and improvement of posterior uveitis score [44]. Recently, comparisons of IFX vs IFN $\alpha$ are also published revealing a similar efficacy of both drugs for uveitis $[45,46]$. There are also some open-label cases showing the efficacy of pegylated IFN $\alpha$ in BD uveitis [47, 48]. Discontinuation of standard IFN $\alpha$ production by pharmaceutical industry and advantage of weekly use may lead to pegylated IFN $\alpha$ use in routine practice. Flulike symptoms, depression, leukopenia, thrombocytopenia, alopecia, and transaminase elevations are reported as side effects with IFN $\alpha$.

IFX and to a lower extend ADA have been used in open studies and case series revealing a lower relapse rate and reduced GC dosage in BD patients with ocular involvement [49-52]. A literature review on TNF $\alpha$ inhibitors showed a sustained response in $89 \%$ of patients with uveitis treated with IFX and in all patients with ADA [19]. Two RCTs reported the efficacy of ADA in patients with non-infectious uveitis $[51,53]$. ADA has been approved for the treatment of noninfectious intermediate, posterior, and panuveitis by the European Medicines Evaluation Agency and Food and Drug Administration based on these RCTs. However, these studies included few BD patients, and the data of BD patients was not reported separately.

There are also some studies comparing the responses of IFX vs ADA for ocular involvement in BD [54]. In a multicenter, observational study including 160 patients, IFX and ADA were found equally effective [55]. In another study of 177 patients from Spain, patients receiving ADA had significantly better improvement in vitritis and best-corrected visual acuity than those receiving IFX. Improvement in retinal vasculitis, however, was similar in both groups. The drug retention rate was also higher in the ADA group [56॰]. Other studies confirmed the efficacy and safety of IFX [57] and ADA [51] for the treatment of ocular involvement. Discontinuation of IFX after remission is also possible. In one study, $32 \%$ were able to discontinue IFX after 20 months of treatment and had 
only $12.5 \%$ relapse rate in 38 months of follow-up [58]. Two studies also reported that early initiation of IFX ( $<18$ months) in $\mathrm{BD}$ uveitis led to better outcomes of ocular involvement in BD (best-corrected visual acuity 100\%) [59, 60].

Observational studies reported that IL-1 inhibition can be an effective and safe option for the treatment of refractory ocular involvement in BD [61-63]. In an open-label pilot study and a randomized phase 2 trial, XOMA-052 (gevokizumab), a recombinant humanized anti-interleukin$1 \beta$ antibody, provided a rapid response and decreased ocular inflammation in BD patients refractory to cISs $[64,65]$. In the phase 3 trial, however, gevokizumab did not reach the primary end-point which was "the time to the first acute ocular exacerbation" [66]. There are also some data indicating the possible efficacy of tocilizumab [67, 68], rituximab [69], and alemtuzumab (humanized monoclonal antibody against CD52) in refractory ocular involvement in BD patients [70].

Ocular involvement contributes most to the morbidity in BD. Despite IS treatments, up to $15 \%$ of the patients with uveitis may still have severe vision loss in recent series. Early onset ( $<25$ years of age) and male gender are the main risk factors for disease severity. Therefore, close collaboration with an expert ophthalmologist is essential for early diagnosis and treatment initiation. All BD patients should be seen by an ophthalmologist at the onset and at regular intervals of 1-2 years even without ocular symptoms, especially during the first 5-10 years of diagnosis. According to 2018 EULAR recommendations for the management of $\mathrm{BD}$, "any ocular $\mathrm{BD}$ patient presenting with posterior segment involvement should be treated with systemic GCs in combination with systemic ISs including azathioprine, cyclosporine $\mathrm{A}, \mathrm{IFN} \alpha$ or monoclonal TNF $\alpha$ inhibitors. If the patient has initial or recurrent acute sight-threatening uveitis, IFX or INF $\alpha$ in combination with high-dose systemic GCs are recommended. Intravitreal glucocorticoid injection can also be added to the systemic regimen especially in unilateral cases. In patients presenting with isolated anterior uveitis, topical agents are often beneficial, but systemic ISs may be needed when hypopyon is present or when patients are at high risk for ocular disease progression (young male patients with earlyonset disease)" [16••].

\section{Vascular Involvement}

Vessel-wall inflammation (vasculitis) is the primary pathology of vascular involvement in BD requiring ISs in the vast majority of cases. Recently, increased venous vessel-wall thickness is shown with Doppler US assessment in femoral and other lower extremity veins and suggested as a diagnostic test for BD [71•]. However, there are no controlled studies of ISs in vascular BD. In an early RCT of ocular disease, vascular and neurological involvement was less present among patients who had been treated with azathioprine [8]. Retrospective case series also confirmed the beneficial effects of azathioprine on vascular inflammation $[72,73]$. In a recent prospective, uncontrolled study comparing azathioprine with IFN $\alpha$, the relapse rate was lower and recanalization rate higher with IFN $\alpha[74 \bullet]$. Another retrospective study comparing biological treatments and cISs including azathioprine, cyclosporine A, and cyclophosphamide in patients with vascular involvement indicated that vascular relapse rate was lower in patients treated with ADA-based regimens compared to patients treated with cISs [75]. TNF $\alpha$ inhibitors seem to be effective treatment options in all types of refractory vascular involvement of BD [76-79]. There are limited data suggesting the efficacy of other biological agents such as anakinra [26], alemtuzumab [70], and tocilizumab [80] in refractory cases. Tofacitinib was also reported to lead to a favorable outcome in patients with BD-related vasculitis [81].

There is no consensus for the use of anticoagulant, antiplatelet, or antifibrinolytic agents in vascular BD. Data for anticoagulation comes from retrospective studies only. In a large vascular BD cohort from France with 99\% anticoagulation, 63\% GC, and 47\% IS use, only ISs are associated with lower venous relapse rate in multivariate analysis [73]. Although $15 \%$ of patients in this cohort had arterial aneurysms ( 8 of which were pulmonary), only $2 \%$ of patients had hemorrhagic complications. In a multi-center study from Turkey, the relapse rate was similar between patients using ISs vs those receiving anticoagulants plus ISs [82]. A meta-analysis of three retrospective studies also showed that ISs and anticoagulants are superior to anticoagulants alone (RR 0.17), and adding anticoagulants to ISs provided no additional benefit (RR 0.75) [16••].

According to EULAR 2018 recommendations, GCs and ISs such as azathioprine, cyclophosphamide, or cyclosporine A are recommended for the management of acute deep venous thrombosis (DVT) in BD. Monoclonal TNF $\alpha$ inhibitors can be considered in refractory patients. For the management of arterial aneurysms and/or occlusion, cyclophosphamide and high-dose GCs are recommended. As a general approach in daily practice, life-threatening conditions such as pulmonary arterial aneurysms and Budd-Chiari syndrome are managed with more aggressive medical treatments including cyclophosphamide and GC pulses. Monoclonal TNF $\alpha$ inhibitors should be considered in refractory cases. Anticoagulants are not routinely recommended due to fatal bleeding risk from coexisting pulmonary arterial aneurysm. They can be added to ISs provided the risk of bleeding is generally low and coexistent pulmonary artery aneurysms are ruled out [16••].

\section{Neurological Involvement}

Neurologic involvement manifests either as parenchymal involvement or cerebral venous sinus thrombosis (CST). Both 
types are rarely seen together in the same patient. When a patient is diagnosed with CST, the patient should be screened for other vascular sites especially for DVT, as extraneurologic vascular involvement is frequently present $(62.5 \%$ in one series) in these patients [83]. No controlled studies are present for the management of neurologic involvement in BD (NBD). According to EULAR 2018 recommendations, azathioprine and daily IV GC pulses (up to 7 day) are usually prescribed as first-line treatment of an acute attack of parenchymal involvement. There are increasing data indicating efficacy of both IFX and ADA in refractory NBD [84-86]. TNF $\alpha$ inhibitors should be used for relapsing or refractory patients and patients with chronic progressive neurologic involvement. For the treatment of CST, high-dose GCs and a short 6-month course of anticoagulation are recommended [16••]. Azathioprine should be the first choice of maintenance treatment in these patients with CST.

Treatment with IV pulse cyclophosphamide, which is considered first-line option in primary CNS vasculitis, led to a lower relapse rate in NBD as compared to azathioprine but only during the first year of follow-up. After up to 10 years of follow-up, there was no difference between IV pulse cyclophosphamide and azathioprine anymore [87]. Event-free survival was also similar among patients receiving cyclophosphamide, azathioprine, or GSs alone [88]. A meta-analysis of observational studies revealed that cyclosporine $\mathrm{A}$ increased the risk of neurologic involvement in uveitis patients (RR: 12.7). Therefore, EULAR recommends avoiding cyclosporine A in BD with neurologic involvement. In small retrospective case series, tocilizumab was also reported as an effective treatment option in refractory NBD patients [89-91]. There are also a few case reports suggesting effectiveness of intravenous immunoglobulins and rituximab in refractory NBD [92-94].

\section{Gastrointestinal Involvement}

Treatment approaches for the management of gastrointestinal disease in $\mathrm{BD}$ are based on retrospective observational studies or extrapolations from studies on inflammatory bowel disease since there are no controlled trials. 5-aminosalicylic acid (ASA) derivatives with/without GCs are suggested as firstline treatment options for mild GI involvement in BD [95]. Azathioprine is used as the first-line treatment in more moderate-severe cases and as an alternative in patients who are refractory to 5-ASA derivatives [96]. Azathioprine also reduced the relapse risk after surgical interventions [97].

In an open-label uncontrolled study including patients with refractory GI involvement, ADA led to the improvement of symptoms and to a reduction of endoscopic findings in most patients. Complete remission was achieved in $20 \%$ of patients after 52-week follow-up [98]. In another open-label study,
IFX induced clinical improvement and resulted in a decrement of inflammatory markers within 2 weeks [76]. Many case series have confirmed that treatment with either IFX or ADA achieved complete remission rates of $20-64 \%$ in patients with refractory GI involvement [86, 99-101]. Data for IL-1 and IL-6 inhibition for the treatment of this manifestation are limited to case reports $[26,63,102]$.

\section{Safety Issues}

With similar efficacies, safety issues may affect the choice of treatment especially between TNF $\alpha$ inhibitors and IFN $\alpha$ in BD patients with refractory major organ involvement. Possibly due to concomitant high-dose GCs, opportunistic infections, especially tuberculosis, are more commonly observed in BD patients under TNF $\alpha$ inhibitors compared to patients with other rheumatological disorders $(7.5 \%$ vs $0.8 \%$ in our series, $3.9 \%$ vs $0.9 \%$ in a literature summary of 4 series) (unpublished observation). This issue is important in countries with a high background rate of tuberculosis prevalence and require careful scrutiny of latent-tuberculosis in these patients.

IFN $\alpha$ do not seem to increase the risk of infections. However, constitutional symptoms, especially with daily high doses during remission-induction phase, lead to a poor $\mathrm{QoL}$ and high drug discontinuation rates in $\mathrm{BD}$ patients. A higher incidence of depression is also reported when using IFN $\alpha$ [103]. No new safety signals are reported with other biological agents.

BD patients have a higher risk of malignancies, especially hematological (RR: 2.58) and thyroid cancers (RR: 1.25) [104]. Interestingly, azathioprine is associated with a lower cancer risk in BD patients. This observation may be explained by selection (funneling) bias, as azathioprine is used more in mild cases, whereas biologics are preferred in patients with severe disease manifestations [104, 105]. Among cISs, cyclophosphamide should be reserved for remission induction in patients with severe arterial disease due to its high teratogenicity and risk for causing malignancy [106]. Hepatotoxicity, cytopenias, and gastro-intestinal intolerance are among the main limitations of cIS use; however, their relative safety for infections is important for long-term management decisions.

\section{Approach to Oral Health in BD}

Oral health is impaired in BD patients, and oral ulcers affect oral quality of life [107]. Oral health is also a mediator of disease severity [108]. Modulation of oral health by dental/ periodontal treatments improve oral health in $\mathrm{BD}$ patients and decrease the number and duration of oral ulcers [109]. Therefore, all BD patients should be encouraged to have routine oral examinations in addition to urgent dental/periodental 
care. In cases where standard oral interventions are not feasible or sufficient, short-term macrolide treatment (azithromycin $500 \mathrm{mg} / 3$ days) might decrease both periodontal infections and oral ulcers [110].

\section{Conclusion}

There are only a few RCTs in BD, mostly conducted in patients with mucocutaneous and/or ocular involvement. There are no RCTs for vascular, neurological, and gastrointestinal disease. Apremilast is now accepted as a new safe and effective treatment option for oral ulcers and is approved by the FDA. Azathioprine is still the first-line conventional IS agent for both major organ disease and refractory mucocutaneous involvement. Increasing data coming from large case series confirmed both the efficacy and safety of TNF $\alpha$ inhibitors for refractory major organ involvements such as ocular, vascular, neurological, and GI disease. In refractory ocular and vascular disease, long-term studies also confirmed the efficacy and safety of IFN $\alpha$. There are quite promising results with anakinra and ustekinumab for the treatment of refractory mucocutaneous disease. IL-1 inhibitors and tocilizumab may be alternatives in patients with refractory ocular involvement. Further randomized controlled studies with biologic agents are needed for the assessment of efficacy, safety, and optimal treatment duration in BD. Also the role of anticoagulants for vascular disease and the benefit of concomitant IS usage with biologics should be investigated in BD.

\section{Declarations}

Conflict of Interest Haner Direskeneli participated in the phase 3 study of apremilast by Celgene as a local Principal Investigator. Fatma AlibazOner declares that she has no conflict of interest.

Human and Animal Rights and Informed Consent This article does not contain any studies with human or animal subjects performed by any of the authors.

\section{References}

Papers of particular interest, published recently, have been highlighted as:

- Of importance

- Of major importance

1. Kural-Seyahi E, Fresko I, Seyahi N, Ozyazgan Y, Mat C, Hamuryudan $\mathrm{V}$, et al. The long-term mortality and morbidity of Behçet syndrome: a 2-decade outcome survey of 387 patients followed at a dedicated center. Medicine (Baltimore). 2003;82(1):60-76.
2. McGonagle D, Aydin SZ, Gül A, Mahr A, Direskeneli H. 'MHCI-opathy'-unified concept for spondyloarthritis and Behçet disease. Nat Rev Rheumatol. 2015;11(12):731-40.

3. Gómez-Gómez A, Loza E, Rosario MP, Espinosa G, de Morales J, Herrera JM, et al. Efficacy and safety of immunomodulatory drugs in patients with non-infectious intermediate and posterior uveitis, panuveitis and macular edema: a systematic literature review. Semin Arthritis Rheum. 2020;50(6):1299-306.

4. Celiker H, Kazokoglu H, Direskeneli H. Conventional immunosuppressive therapy in severe Behcet's uveitis: the switch rate to the biological agents. BMC Ophthalmol. 2018;18(1):261.

5. Mat C, Yurdakul S, Uysal S, Gogus F, Ozyazgan Y, Uysal O, et al. A double-blind trial of depot corticosteroids in Behçet's syndrome. Rheumatology (Oxford). 2006;45(3):348-52.

6. Mohammadi M, Shahram F, Shams H, Akhlaghi M, Ashofteh F, Davatchi F. High-dose intravenous steroid pulse therapy in ocular involvement of Behcet's disease: a pilot double-blind controlled study. Int J Rheum Dis. 2017;20(9):1269-76.

7. Piga M, Floris A, Espinosa G, Serpa Pinto L, Kougkas N, Lo Monaco A, et al. Development and preliminary validation of the Behçet's syndrome Overall Damage Index (BODI). RMD Open. 2020;6(2).

8. Hamuryudan V, Ozyazgan Y, Hizli N, Mat C, Yurdakul S, Tüzün $\mathrm{Y}$, et al. Azathioprine in Behcet's syndrome: effects on long-term prognosis. Arthritis Rheum. 1997;40(4):769-74.

9. Martín-Varillas JL, Atienza-Mateo B, Calvo-Rio V, Beltrán E, Sánchez-Bursón J, Adán A, et al. Long term follow-up and optimization of infliximab in refractory uveitis due to Behçet's disease. National study of 103 Caucasian patients. J Rheumatol. 2020.

10. Onal S, Kazokoglu H, Koc A, Akman M, Bavbek T, Direskeneli $\mathrm{H}$, et al. Long-term efficacy and safety of low-dose and doseescalating interferon alfa-2a therapy in refractory Behçet uveitis. Arch Ophthalmol. 2011;129(3):288-94.

11. Cantini F, Niccoli L, Nannini C, Cassarà E, Kaloudi O. Rapid loss of efficacy of biosimilar infliximab in three patients with Behçet's disease after switching from infliximab originator. Eur $\mathrm{J}$ Rheumatol. 2017;4(4):288-90.

12. Lopalco G, Venerito V, Cantarini L, Emmi G, Prisco D, Iannone F. Long-term effectiveness and safety of switching from originator to biosimilar infliximab in patients with Behçet's disease. Intern Emerg Med. 2019;14(5):719-22.

13. Dincses E, Esatoglu SN, Ozguler Y, Uygunoglu U, Hamuryudan V, Seyahi E, et al. Biosimilar infliximab for Behçet's syndrome: a case series. Clin Exp Rheumatol. 2019;37 Suppl 121(6):111-5.

14. Xue L, van Bilsen K, Schreurs MWJ, van Velthoven MEJ, Missotten TO, Thiadens A, et al. Are patients at risk for recurrent disease activity after switching from Remicade(®) to Remsima(®)? An observational study. Front Med (Lausanne). 2020;7:418.

15. Akiyama S, Hamdeh S, Micic D, Sakuraba A. Prevalence and clinical outcomes of COVID-19 in patients with autoimmune diseases: a systematic review and meta-analysis. Ann Rheum Dis. 2020.

16•• Hatemi G, Christensen R, Bang D, Bodaghi B, Celik AF, Fortune F, et al. 2018 update of the EULAR recommendations for the management of Behçet's syndrome. Ann Rheum Dis. 2018;77(6):808-18 The most important current Recommendation for the Management of BD.

17. Alibaz-Oner F, Mumcu G, Kubilay Z, Ozen G, Celik G, Karadeniz A, et al. Unmet need in Behcet's disease: most patients in routine follow-up continue to have oral ulcers. Clin Rheumatol. 2014;33(12):1773-6.

18. Melikoglu M, Fresko I, Mat C, Ozyazgan Y, Gogus F, Yurdakul $\mathrm{S}$, et al. Short-term trial of etanercept in Behcet's disease: a double blind, placebo controlled study. J Rheumatol. 2005;32(1):98-105. 
19. Arida A, Fragiadaki K, Giavri E, Sfikakis PP. Anti-TNF agents for Behçet's disease: analysis of published data on 369 patients. Semin Arthritis Rheum. 2011;41(1):61-70.

20. Hatemi G, Melikoglu M, Tunc R, Korkmaz C, Turgut Ozturk B, Mat C, et al. Apremilast for Behçet's syndrome-a phase 2, placebo-controlled study. N Engl J Med. 2015;372(16):1510-8.

21••. Hatemi G, Mahr A, Ishigatsubo Y, Song YW, Takeno M, Kim $\mathrm{D}$, et al. Trial of apremilast for oral ulcers in Behçet's syndrome. N Engl J Med. 2019;381(20):1918-28 An important Phase-3 study demonstrating the efficacy and safety of Apremilast for oral ulcer treatment in BD patients.

22. Lopalco G, Venerito V, Leccese P, Emmi G, Cantarini L, Lascaro $\mathrm{N}$, et al. Real-world effectiveness of apremilast in multirefractory mucosal involvement of Behçet's disease. Ann Rheum Dis. 2019;78(12):1736-7.

23. De Luca G, Cariddi A, Campochiaro C, Vanni D, Boffini N, Tomelleri A, et al. Efficacy and safety of apremilast for Behçet's syndrome: a real-life single-centre Italian experience. Rheumatology (Oxford). 2020;59(1):171-5.

24. Hirahara L, Kirino Y, Soejima Y, Takeno M, Takase-Minegishi $\mathrm{K}$, Yoshimi R, et al. Efficacy and safety of apremilast for 3 months in Behçet's disease: a prospective observational study. Mod Rheumatol. 2020:1-6.

25. Vitale A, Rigante D, Caso F, Brizi MG, Galeazzi M, Costa L, et al. Inhibition of interleukin-1 by canakinumab as a successful monodrug strategy for the treatment of refractory Behçet's disease: a case series. Dermatology. 2014;228(3):211-4.

26. Cantarini L, Vitale A, Scalini P, Dinarello CA, Rigante D, Franceschini R, et al. Anakinra treatment in drug-resistant Behcet's disease: a case series. Clin Rheumatol. 2015;34(7): 1293-301.

27. Grayson PC, Yazici Y, Merideth M, Sen HN, Davis M, Novakovich E, et al. Treatment of mucocutaneous manifestations in Behçet's disease with anakinra: a pilot open-label study. Arthritis Res Ther. 2017;19(1):69.

28• Fabiani C, Vitale A, Rigante D, Emmi G, Lopalco G, Di Scala G, et al. The presence of uveitis is associated with a sustained response to the interleukin (IL)-1 inhibitors anakinra and canakinumab in Behçet's disease. Ocul Immunol Inflamm. 2020;28(2):298-304 Study suggesting a beneficial role of anti-IL-1 treatment in BD with uveitis.

29. Mirouse A, Barete S, Monfort JB, Resche-Rigon M, Bouyer AS, Comarmond C, et al. Ustekinumab for Behçet's disease. J Autoimmun. 2017:82:41-6.

30•• Mirouse A, Barete S, Desbois AC, Comarmond C, Sène D, Domont $\mathrm{F}$, et al. Long-term outcome of ustekinumab therapy for Behcet's disease. Arthritis Rheum. 2019;71(10):1727-32 Study suggesting a beneficial role of Ustekinumab in BD.

31. Esatoglu SN, Hatemi G. Update on the treatment of Behçet's syndrome. Intern Emerg Med. 2019;14(5):661-75.

32• Akiyama M, Kaneko Y, Takeuchi T. Effectiveness of tocilizumab in Behcet's disease: a systematic literature review. Semin Arthritis Rheum. 2020;50(4):797-804 A meta-analysis summarizing data on Tocilizumab use in BD.

33. Fagni F, Bettiol A, Talarico R, Lopalco G, Silvestri E, Urban ML, et al. Long-term effectiveness and safety of secukinumab for treatment of refractory mucosal and articular Behçet's phenotype: a multicentre study. Ann Rheum Dis. 2020;79(8):1098-104 Study suggesting a beneficial role of Secukinumab in BD.

34. Yazici H, Pazarli H, Barnes CG, Tüzün Y, Ozyazgan Y, Silman A, et al. A controlled trial of azathioprine in Behçet's syndrome. N Engl J Med. 1990;322(5):281-5.

35. BenEzra D, Cohen E, Chajek T, Friedman G, Pizanti S, de Courten $\mathrm{C}$, et al. Evaluation of conventional therapy versus cyclosporine A in Behçet's syndrome. Transplant Proc. 1988;20(3 Suppl 4):136-43.
36. Ozyazgan Y, Yurdakul S, Yazici H, Tüzün B, Işçimen A, Tüzün Y, et al. Low dose cyclosporin A versus pulsed cyclophosphamide in Behçet's syndrome: a single masked trial. Br J Ophthalmol. 1992;76(4):241-3.

37. Masuda K, Nakajima A, Urayama A, Nakae K, Kogure M, Inaba G. Double-masked trial of cyclosporin versus colchicine and longterm open study of cyclosporin in Behçet's disease. Lancet. 1989;1(8647):1093-6.

38. Eser-Ozturk H, Sullu Y. The results of interferon-alpha treatment in Behcet uveitis. Ocul Immunol Inflamm. 2020;28(3):498-504.

39. Shi J, Zhao C, Zhou J, Liu J, Wang L, Gao F, et al. Effectiveness and safety of interferon $\alpha 2 \mathrm{a}$ as an add-on treatment for refractory Behçet's uveitis. Ther Adv Chronic Dis. 2019;10: 2040622319847881

40• Albayrak O, Oray M, Can F, Uludag Kirimli G, Gul A, TugalTutkun I, et al. Effect of interferon alfa-2a treatment on adaptive and innate immune systems in patients with Behçet disease uveitis. Invest Ophthalmol Vis Sci. 2019;60(1):52-63 Study investigating the mechanism-of-action of IFN $\alpha$ in BD.

41. Kötter I, Günaydin I, Zierhut M, Stübiger N. The use of interferon alpha in Behcet disease: review of the literature. Semin Arthritis Rheum. 2004;33(5):320-35.

42. Diwo E, Gueudry J, Saadoun D, Weschler B, LeHoang P, Bodaghi B. Long-term efficacy of interferon in severe uveitis associated with Behçet disease. Ocul Immunol Inflamm. 2017;25(1):76-84.

43. Deuter CM, Zierhut M, Möhle A, Vonthein R, Stöbiger N, Kötter I. Long-term remission after cessation of interferon- $\alpha$ treatment in patients with severe uveitis due to Behçet's disease. Arthritis Rheum. 2010;62(9):2796-805.

44. Kötter I, Vonthein R, Schoenfisch B, Xenitidis T, Doycheva D, Henes J, et al. AB0545 Interferon Alpha2a versus cyclosporin A for the treatment of severe ocular Behcet's disease - a prospective, randomised, single blind, national multicenter trial (INCYTOB). Ann Rheum Dis. 2016;75(Suppl 2):1091.

45. De Simone L, Invernizzi A, Aldigeri R, Mastrofilippo V, Marvisi $\mathrm{C}$, Gozzi $\mathrm{F}$, et al. Effectiveness of infliximab and interferon alpha2a for the treatment of Behçet's uveitis: customizing therapy according to the Clinical Features. Ocul Immunol Inflamm. 2020:19

46. Yalçindag N, Köse HC. Comparison of the treatment results for Behcet uveitis in patients treated with infliximab and interferon. Ocul Immunol Inflamm. 2020;28(2):305-14.

47. Lightman S, Taylor SR, Bunce C, Longhurst H, Lynn W, Moots $\mathrm{R}$, et al. Pegylated interferon- $\alpha-2 \mathrm{~b}$ reduces corticosteroid requirement in patients with Behçet's disease with upregulation of circulating regulatory T cells and reduction of Th17. Ann Rheum Dis. 2015;74(6):1138-44.

48. Celiker H, Kazokoglu H, Direskeneli H. Long-term efficacy of pegylated interferon alpha- $2 b$ in Behçet's uveitis: a small case series. Ocul Immunol Inflamm. 2019;27(1):15-22.

49. Tugal-Tutkun I, Mudun A, Urgancioglu M, Kamali S, Kasapoglu $\mathrm{E}$, Inanc $\mathrm{M}$, et al. Efficacy of infliximab in the treatment of uveitis that is resistant to treatment with the combination of azathioprine, cyclosporine, and corticosteroids in Behçet's disease: an openlabel trial. Arthritis Rheum. 2005;52(8):2478-84.

50. Sfikakis PP, Kaklamanis PH, Elezoglou A, Katsilambros N, Theodossiadis PG, Papaefthimiou S, et al. Infliximab for recurrent, sight-threatening ocular inflammation in AdamantiadesBehçet disease. Ann Intern Med. 2004;140(5):404-6.

51. Fabiani C, Vitale A, Emmi G, Vannozzi L, Lopalco G, Guerriero $\mathrm{S}$, et al. Efficacy and safety of adalimumab in Behçet's diseaserelated uveitis: a multicenter retrospective observational study. Clin Rheumatol. 2017;36(1):183-9.

52. Calvo-Río V, Blanco R, Beltrán E, Sánchez-Bursón J, Mesquida M, Adán A, et al. Anti-TNF- $\alpha$ therapy in patients with refractory 
uveitis due to Behçet's disease: a 1-year follow-up study of 124 patients. Rheumatology (Oxford). 2014;53(12):2223-31.

53. Nguyen QD, Merrill PT, Jaffe GJ, Dick AD, Kurup SK, Sheppard $\mathrm{J}$, et al. Adalimumab for prevention of uveitic flare in patients with inactive non-infectious uveitis controlled by corticosteroids (VISUAL II): a multicentre, double-masked, randomised, placebo-controlled phase 3 trial. Lancet. 2016;388(10050):118392.

54. Kunimi K, Usui Y, Asakage M, Maehara C, Tsubota K, Mitsuhashi R, et al. Anti-TNF- $\alpha$ therapy for refractory uveitis associated with Behçet's syndrome and sarcoidosis: a single center study of 131 patients. Ocul Immunol Inflamm. 2020:1-8.

55. Vallet H, Seve P, Biard L, Baptiste Fraison J, Bielefeld P, Perard $\mathrm{L}$, et al. Infliximab versus adalimumab in the treatment of refractory inflammatory uveitis: a multicenter study from the French Uveitis Network. Arthritis Rheum. 2016;68(6):1522-30.

56. - Atienza-Mateo B, Martín-Varillas JL, Calvo-Río V, DemetrioPablo R, Beltrán E, Sánchez-Bursón J, et al. Comparative study of infliximab versus adalimumab in refractory uveitis due to Behçet's disease: national multicenter study of 177 cases. Arthritis Rheum. 2019;71(12):2081-9 A comparative study of infliximab vs adalimumab in BD uveitis.

57. Takeuchi M, Kezuka T, Sugita S, Keino H, Namba K, Kaburaki T, et al. Evaluation of the long-term efficacy and safety of infliximab treatment for uveitis in Behçet's disease: a multicenter study. Ophthalmology. 2014;121(10):1877-84.

58. Köse HC, Yalçındağ N. Clinical follow-up of patients with Behçet uveitis after discontinuation of infliximab therapy. Ocul Immunol Inflamm. 2020:1-5

59. Keino H, Okada AA, Watanabe T, Nakayama M, Nakamura T. Efficacy of infliximab for early remission induction in refractory uveoretinitis associated with Behçet disease: a 2-year follow-up study. Ocul Immunol Inflamm. 2017;25(1):46-51.

60. Guzelant G, Ucar D, Esatoglu SN, Hatemi G, Ozyazgan Y, Yurdakul S, et al. Infliximab for uveitis of Behçet's syndrome: a trend for earlier initiation. Clin Exp Rheumatol. 2017;35 Suppl 108(6):86-9.

61. Fabiani C, Vitale A, Emmi G, Lopalco G, Vannozzi L, Guerriero $\mathrm{S}$, et al. Interleukin (IL)-1 inhibition with anakinra and canakinumab in Behçet's disease-related uveitis: a multicenter retrospective observational study. Clin Rheumatol. 2017;36(1):1917.

62. Sota J, Vitale A, Insalaco A, Sfriso P, Lopalco G, Emmi G, et al. Safety profile of the interleukin-1 inhibitors anakinra and canakinumab in real-life clinical practice: a nationwide multicenter retrospective observational study. Clin Rheumatol. 2018;37(8): 2233-40.

63. Emmi G, Talarico R, Lopalco G, Cimaz R, Cantini F, Viapiana O, et al. Efficacy and safety profile of anti-interleukin-1 treatment in Behçet's disease: a multicenter retrospective study. Clin Rheumatol. 2016;35(5):1281-6.

64. Gül A, Tugal-Tutkun I, Dinarello CA, Reznikov L, Esen BA, Mirza A, et al. Interleukin-1ß-regulating antibody XOMA 052 (gevokizumab) in the treatment of acute exacerbations of resistant uveitis of Behcet's disease: an open-label pilot study. Ann Rheum Dis. 2012;71(4):563-6.

65. Tugal-Tutkun IM, Kadayifcilar SM, Khairallah MM, Lee SCMP, Ozdal P, Özyazgan Y, et al. Safety and efficacy of gevokizumab in patients with Behçet's disease uveitis: results of an exploratory phase 2 study. Ocul Immunol Inflamm. 2017;25(1):62-70.

66. Tugal-Tutkun I, Pavesio C, De Cordoue A, Bernard-Poenaru O, Gül A. Use of gevokizumab in patients with Behçet's disease uveitis: an international, randomized, double-masked, placebocontrolled study and open-label extension study. Ocul Immunol Inflamm. 2018;26(7):1023-33.
67. Atienza-Mateo B, Calvo-Río V, Beltrán E, Martínez-Costa L, Valls-Pascual E, Hernández-Garfella M, et al. Anti-interleukin 6 receptor tocilizumab in refractory uveitis associated with Behçet's disease: multicentre retrospective study. Rheumatology (Oxford). 2018;57(5):856-64.

68. Eser Ozturk H, Oray M, Tugal-Tutkun I. Tocilizumab for the treatment of Behçet uveitis that failed interferon alpha and antitumor necrosis factor-alpha therapy. Ocul Immunol Inflamm. 2018;26(7):1005-14.

69. Davatchi F, Shams H, Rezaipoor M, Sadeghi-Abdollahi B, Shahram F, Nadji A, et al. Rituximab in intractable ocular lesions of Behcet's disease; randomized single-blind control study (pilot study). Int J Rheum Dis. 2010;13(3):246-52.

70. Mohammad AJ, Smith RM, Chow YW, Chaudhry AN, Jayne DR. Alemtuzumab as remission induction therapy in Behçet disease: a 20-year experience. J Rheumatol. 2015;42(10):1906-13.

71. - Alibaz-Oner F, Ergelen R, Yildiz Y, Aldag M, Yazici A, Cefle A, et al. Femoral vein wall thickness measurement: a new diagnostic tool for Behcet's disease. Rheumatology (Oxford). 2020. Study demonstrating a high sensitivity and specificity of Doppler US to measure venous-wall thickness in BD.

72. Tascilar K, Melikoglu M, Ugurlu S, Sut N, Caglar E, Yazici H. Vascular involvement in Behçet's syndrome: a retrospective analysis of associations and the time course. Rheumatology (Oxford). 2014;53(11):2018-22.

73. Desbois AC, Wechsler B, Resche-Rigon M, Piette JC, Huong Dle $\mathrm{T}$, Amoura Z, et al. Immunosuppressants reduce venous thrombosis relapse in Behçet's disease. Arthritis Rheum. 2012;64(8): 2753-60.

74. • Ozguler Y, Hatemi G, Cetinkaya F, Tascilar K, Hamuryudan V, Ugurlu S, et al. Clinical course of acute deep vein thrombosis of the legs in Behçet's syndrome, Rheumatology (Oxford). 2020;59(4):799-806 Study demonstrating the beneficial role of IFN $\alpha$ in vascular BD.

75. Emmi G, Vitale A, Silvestri E, Boddi M, Becatti M, Fiorillo C, et al. Adalimumab-based treatment versus disease-modifying antirheumatic drugs for venous thrombosis in Behçet's syndrome: a retrospective study of seventy patients with vascular involvement. Arthritis Rheum. 2018;70(9):1500-7.

76. Hibi T, Hirohata S, Kikuchi H, Tateishi U, Sato N, Ozaki K, et al. Infliximab therapy for intestinal, neurological, and vascular involvement in Behcet disease: efficacy, safety, and pharmacokinetics in a multicenter, prospective, open-label, single-arm phase 3 study. Medicine (Baltimore). 2016;95(24):e3863.

77. Desbois AC, Biard L, Addimanda O, Lambert M, Hachulla E, Launay D, et al. Efficacy of anti-TNF alpha in severe and refractory major vessel involvement of Behcet's disease: A multicenter observational study of 18 patients. Clin Immunol. 2018;197:54-9.

78. Aksoy A, Yazici A, Omma A, Cefle A, Onen F, Tasdemir U, et al. Efficacy of TNF $\alpha$ inhibitors for refractory vascular Behçet's disease: a multicenter observational study of 27 patients and a review of the literature. Int J Rheum Dis. 2020;23(2):256-61.

79. Kehribar DY, Ozgen M. Infliximab treatment in refractory vascular Behcet's disease: a single-center experience. Vascular. 2020;28(6):829-33.

80. Ding Y, Li C, Liu J, Yu X, Wang Y, Shi J, et al. Tocilizumab in the treatment of severe and/or refractory vasculo-Behçet's disease: a single-centre experience in China. Rheumatology (Oxford). 2018;57(11):2057-9.

81. Liu J, Hou Y, Sun L, Li C, Li L, Zhao Y, et al. A pilot study of tofacitinib for refractory Behçet's syndrome. Ann Rheum Dis. 2020;79(11):1517-20.

82. Alibaz-Oner F, Karadeniz A, Ylmaz S, Balkarl A, Kimyon G, Yazc A, et al. Behçet disease with vascular involvement: effects of different therapeutic regimens on the incidence of new relapses. Medicine (Baltimore). 2015;94(6):e494. 
83. Saadoun D, Wechsler B, Resche-Rigon M, Trad S, Le Thi HD, Sbai A, et al. Cerebral venous thrombosis in Behçet's disease. Arthritis Rheum. 2009;61(4):518-26.

84. Zeydan B, Uygunoglu U, Saip S, Demirci ON, Seyahi E, Ugurlu $\mathrm{S}$, et al. Infliximab is a plausible alternative for neurologic complications of Behçet disease. Neurol Neuroimmunol Neuroinflamm. 2016;3(5):e258.

85. Desbois AC, Addimanda O, Bertrand A, Deroux A, Pérard L, Depaz R, et al. Efficacy of anti-TNF $\alpha$ in severe and refractory neuro-Behcet disease: an observational study. Medicine (Baltimore). 2016;95(23):e3550.

86. Vallet H, Riviere S, Sanna A, Deroux A, Moulis G, Addimanda O, et al. Efficacy of anti-TNF alpha in severe and/or refractory Behçet's disease: multicenter study of 124 patients. J Autoimmun. 2015;62:67-74.

87. Ozguler Y, Leccese P, Christensen R, Esatoglu SN, Bang D, Bodaghi B, et al. Management of major organ involvement of Behcet's syndrome: a systematic review for update of the EULAR recommendations. Rheumatology (Oxford). 2018;57(12):2200-12.

88. Noel N, Bernard R, Wechsler B, Resche-Rigon M, Depaz R, Le Thi Huong Boutin D, et al. Long-term outcome of neuro-Behçet's disease. Arthritis Rheum. 2014;66(5):1306-14.

89. Addimanda O, Pipitone N, Pazzola G, Salvarani C. Tocilizumab for severe refractory neuro-Behçet: three cases IL-6 blockade in neuro-Behcet. Semin Arthritis Rheum. 2015;44(4):472-5.

90. Urbaniak P, Hasler P, Kretzschmar S. Refractory neuro-Behçet treated by tocilizumab: a case report. Clin Exp Rheumatol. 2012;30(3 Suppl 72):S73-5.

91. Shapiro LS, Farrell J, Borhani HA. Tocilizumab treatment for neuro-Behcet's disease, the first report. Clin Neurol Neurosurg. 2012;114(3):297-8.

92. Cantarini L, Stromillo ML, Vitale A, Lopalco G, Emmi G, Silvestri E, et al. Efficacy and safety of intravenous immunoglobulin treatment in refractory Behcet's disease with different organ involvement: a case series. Isr Med Assoc J. 2016;18(3-4):23842.

93. Kidd DP. Rituximab is effective in severe treatment-resistant neurological Behçet's syndrome. J Neurol. 2015;262(12):2676-7.

94. Jade J, Chung K, Arendse M, Hussain Z, White D. NeuroBehçet's disease presenting with tumour-like lesions and responding to rituximab. J Clin Neurosci. 2016;32:139-41.

95. Jung YS, Hong SP, Kim TI, Kim WH, Cheon JH. Long-term clinical outcomes and factors predictive of relapse after 5aminosalicylate or sulfasalazine therapy in patients with intestinal Behcet disease. J Clin Gastroenterol. 2012;46(5):e38-45.

96. Jung YS, Cheon JH, Hong SP, Kim TI, Kim WH. Clinical outcomes and prognostic factors for thiopurine maintenance therapy in patients with intestinal Behcet's disease. Inflamm Bowel Dis. 2012;18(4):750-7.

97. Hatemi I, Esatoglu SN, Hatemi G, Erzin Y, Yazici H, Celik AF. Characteristics, treatment, and long-term outcome of gastrointestinal involvement in Behcet's syndrome: a strobe-compliant observational study from a dedicated multidisciplinary center. Medicine (Baltimore). 2016;95(16):e3348.
98. Tanida S, Inoue N, Kobayashi K, Naganuma M, Hirai F, Iizuka B, et al. Adalimumab for the treatment of Japanese patients with intestinal Behçet's disease. Clin Gastroenterol Hepatol. 2015;13(5):940-8.e3.

99. Zou J, Ji DN, Cai JF, Guan JL, Bao ZJ. Long-term outcomes and predictors of sustained response in patients with intestinal Behcet's disease treated with infliximab. Dig Dis Sci. 2017;62(2):441-7.

100. Inoue N, Kobayashi K, Naganuma M, Hirai F, Ozawa M, Arikan $\mathrm{D}$, et al. Long-term safety and efficacy of adalimumab for intestinal Behçet's disease in the open label study following a phase 3 clinical trial. Intest Res. 2017;15(3):395-401.

101. Lee JH, Cheon JH, Jeon SW, Ye BD, Yang SK, Kim YH, et al. Efficacy of infliximab in intestinal Behçet's disease: a Korean multicenter retrospective study. Inflamm Bowel Dis. 2013;19(9): 1833-8.

102. Chen J, Chen S, He J. A case of refractory intestinal Behcet's disease treated with tocilizumab, a humanised anti-interleukin-6 receptor antibody. Clin Exp Rheumatol. 2017;35 Suppl 108(6): $116-8$.

103. Keskin Y, Seyahi E, Poyraz C, Ugurlu S, Ozyazgan Y, Yazici H. Interferon alfa-associated depression in patients with Behçet's syndrome: a prospective controlled study. Clin Exp Rheumatol. 2014;32(4 Suppl 84):S175.

104. Jung YS, Han M, Kim DY, Cheon JH, Park S. Cancer risk in Korean patients with Behçet's disease: a nationwide populationbased study. PLoS One. 2017;12(12):e0190182.

105. Guven DC, Bolek EC, Altintop SE, Celikten B, Aktas BY, Kiraz $\mathrm{S}$, et al. Cancer incidence in Behcet's disease. Ir J Med Sci. 2020;189(4):1209-14.

106. Gurcan M, Esatoglu SN, Hamuryudan V, Saygin D, Ugurlu S, Seyahi E, et al. Long term follow-up of Behçet's syndrome patients treated with cyclophosphamide. Rheumatology (Oxford). 2020;59(9):2264-71.

107. Mumcu G, Direskeneli H. Triggering agents and microbiome as environmental factors on Behçet's syndrome. Intern Emerg Med. 2019;14(5):653-60.

108. Yay M, Çelik Z, Aksoy A, Alibaz-Öner F, Inanç N, Ergun T, et al. Oral health is a mediator for disease severity in patients with Behçet's disease: a multiple mediation analysis study. J Oral Rehabil. 2019;46(4):349-54.

109. Karacayli U, Mumcu G, Simsek I, Pay S, Kose O, Erdem H, et al. The close association between dental and periodontal treatments and oral ulcer course in Behcet's disease: a prospective clinical study. J Oral Pathol Med. 2009;38(5):410-5.

110. Mumcu G, Inanç N, Özdemir FT, Tulunay A, Ekșioğlu-Demiralp $\mathrm{E}$, Ergun T, et al. Effects of azithromycin on intracellular cytokine responses and mucocutaneous manifestations in Behçet's disease. Int J Dermatol. 2013;52(12):1561-6.

Publisher's Note Springer Nature remains neutral with regard to jurisdictional claims in published maps and institutional affiliations. 